\title{
REVISTA BRASILEIRA DE
}

AGRICULTURA IRRIGADA

Revista Brasileira de Agricultura Irrigada v.11, nº.8, p. 2120 - 2131, 2017

ISSN 1982-7679 (On-line)

Fortaleza, CE, INOVAGRI - http://www.inovagri.org.br

DOI: $10.7127 /$ rbai.v11n800692

Protocolo 692.17 - 31/05/2017 Aprovado em 06/09/2017

\section{EFEITO DA SALINIDADE NO CRESCIMENTO E PRODUÇÃO DO TOMATE CULTIVADO EM AMBIENTE PROTEGIDO ${ }^{1}$}

\author{
Miguel Augusto Viol ${ }^{2}$, Jacinto de Assunção Carvalho ${ }^{3}$, Elvis Márcio de Castro Lima ${ }^{4}$, Fátima \\ Conceição Rezende ${ }^{5}$, Luíz Antônio Augusto Gomes ${ }^{6}$
}

\section{RESUMO}

A qualidade da água e o manejo inadequado da fertirrigação podem causar sérios problemas de salinização do solo, principalmente em cultivos protegidos em que a irrigação é a única fonte de fornecimento de água às plantas. Este trabalho teve por objetivo avaliar o efeito da aplicação de água com diferentes níveis de salinidade na produção do tomate cultivado em ambiente protegido. As plantas foram transplantadas em vasos com capacidade de $20 \mathrm{~L}$, colocados sobre uma plataforma de 0,20 m de altura, e espaçamento de 0,60 m entre as plantas e 1,00 m entre as fileiras. Utilizou-se um sistema de irrigação por gotejamento. O experimento foi conduzido em um delineamento inteiramente casualizado, com 5 níveis de salinidade da água de irrigação $\left(\mathrm{S} 1=0,018 ; \mathrm{S} 2=1,5 ; \mathrm{S} 3=3,5\right.$ e $\mathrm{S} 4=5,5$ e $\mathrm{S} 56,5 \mathrm{dS} \mathrm{m}^{-1}$ a $\left.25^{\circ} \mathrm{C}\right)$ e cinco repetições. Foram analisados o diâmetro e altura das plantas, na colheita os frutos foram pesados e medido o diâmetro para classificação. No final do experimento foi medida a área foliar e determinado o peso da matéria seca da parte aérea da planta. As produções total e comercial, e a área foliar reduziram com o aumento da salinidade da água de irrigação. A redução na produção total devido ao uso de água com concentração de sais de $6,5 \mathrm{dS} \mathrm{m}^{-1}$ foi de $88,7 \%$ e na produção comercial foi de $92,5 \%$.

Palavras-chave: água salina, produção comercial, queda de produção

\footnotetext{
${ }^{1}$ Projeto financiado pela FAPEMIG

2 Departamento de Engenharia, Universidade Federal de Lavras, Lavras, Brasil, caixa postal 3037, e-mail: gutoviol@hotmail.com

3 Departamento de Engenharia, Universidade Federal de Lavras, Lavras, Brasil, caixa postal 3037, email:Jacintoc@deg.ufla.br

4 Departamento de Engenharia, Universidade Federal de Lavras, Lavras, Brasil, caixa postal 3037, email:elvis.lima@deg.ufla.br

5 Departamento de Engenharia, Universidade Federal de Lavras, Lavras, Brasil, caixa postal 3037, email: frezende@deg.ufla.br

6 Departamento de Agricultura, Universidade Federal de Lavras, Lavras, Brasil, caixa postal, email: laagomes@dag.ufla.br
} 


\title{
SALINITY EFFECTS OF GROWTH AND PRODUCTION OF TOMATO CULTIVATED IN GREENHOUSE
}

\begin{abstract}
Water quality and inadequate management of fertigation can cause serious problems of soil salinization especially in crops protected environment where irrigation is the only source of water supply the plants. This study aimed to evaluate the effect of water with different salinity levels in the production of tomatoes plants in greenhouse. The plants were transplanted into pots with $20 \mathrm{~L}$ capacity, placed on a platform of $0.20 \mathrm{~m}$ high and $0.60 \mathrm{~m}$ spacing between plants and $1.00 \mathrm{~m}$ between rows. It was used a drip irrigation system. The experiment was conducted in a completely randomized design with 5 irrigation water salinity levels $(\mathrm{S} 1=0.018 ; \mathrm{S} 2=1.5 ; 3.5=$ $\mathrm{S} 3$ and S4 and S5 $6.5=5.5 \mathrm{dS} \mathrm{m}^{-1}$ at $25^{\circ} \mathrm{C}$ ) and five replication. The diameter and height of plants was analyzed. At the harvest the fruit was weight and classified according to diameter. At the end of experiment the leaf area was measured and the dry matter of the aerial part of the plant was weighed. The total and marketable yield decreased with increasing for irrigation water salinity. The reduction in total production due to the use of saline water with a concentration of $6.5 \mathrm{dS} \mathrm{m}-1$ salts was $88.7 \%$ and reduction in commercial production was $92.5 \%$.
\end{abstract}

Keywords: Saline Water, commercial production, production fall

\section{INTRODUÇÃO}

A salinidade do solo causada pelo uso indevido de fertilizantes e por água de baixa qualidade causa danos severos às plantas e ao solo. Devido à expansão das áreas irrigadas e a limitada disponibilidade de água de boa qualidade será necessário utilizar água residuária na irrigação. Entretanto, a água residuária poderá apresentar baixa qualidade devido à presença de elementos químicos que podem promover a salinização dos solos.

Em ambiente protegido, a aplicação de fertilizantes via irrigação pode elevar os níveis de salinidade do solo, uma vez que não há a lavagem dos sais pela água de chuvas e, reduzir a produtividade ao longo de sucessivos ciclos de cultivo.

O tomate é uma das hortaliças mais cultivadas em ambiente protegido, principalmente nas regiões Sul e Sudeste do Brasil e, o cultivo se dá mediante o uso frequente da fertirrigação (ELOI et al. 2007). Com relação à salinidade a cultura é considerada medianamente sensível tendo como limite de tolerância $2,5 \mathrm{dS} \mathrm{m}^{-1}$, determinados no extrato de saturação do solo e, para cada unidade de acréscimo na salinidade, acima deste limite, há uma redução de $9,9 \%$ na produtividade (MAAS; HOFFMAN, 1977).

Estudos tem demonstrado que a salinidade tem efeito negativo no crescimento das plantas, na massa seca total, no tamanho dos frutos, na produtividade e na incidência de podridão apical na cultura de tomate, entre outros (CAMPOS et al., 2006; CANTORE et al., 2012; ELOI et al., 2007; LEOGRANDE et al., 2012; MEDEIROS et al., 2012). Aumento na qualidade do fruto com a salinidade, tais como, o conteúdo de sólidos solúveis totais, a acidez titulável e o sabor dos frutos têm sido observados em vários estudos (CLIFF et al., 2012, LEOGRANDE et al., 2011, MALASH et al., 2008).

Campos et al. (2006), compararam o efeito de cinco níveis de salinidade $(1,2,3$, 4, e $\left.5 \mathrm{dS} \mathrm{m}^{-1}\right)$ da água de irrigação no tomate para a indústria e concluíram que a produtividade total reduziu em $11 \%$ para cada unidade de acréscimo na salinidade da 
água, enquanto que a qualidade do fruto aumentou com o acréscimo da salinidade. Entretanto, de acordo com Malash et al. (2005), na adoção de irrigação com água salina deve ser considerado a sensibilidade da cultura à salinidade da água nos diferentes estágios de desenvolvimento. Ainda de acordo com os autores, quando se usa água salina, deve ser considerado a tolerância da cultura, o sistema de irrigação, as estratégias de manejo, a frequência da irrigação e as propriedades do solo. Wan et al. (2007), conduziram um experimento em campo no norte da China e concluíram que quando se aplica água salina por aproximadamente 30 dias após o plantio, a salinidade da água variando de 1,1 a $4,9 \mathrm{dS} \mathrm{m}^{-1}$ teve pouco efeito na produtividade do tomate.

Pesquisa realizada por Cantore et al. (2012), comparando 3 níveis de salinidade da água de irrigação( $0,5,5$ e $\left.10 \mathrm{dS} \mathrm{m}{ }^{-1}\right), 3$ regimes de irrigação (20, 40 e $60 \%$ do esgotamento da água disponível) e duas cultivares de tomate, foi observado que o aumento da salinidade da água promoveu redução no peso, no comprimento e na largura dos frutos e aumentou a incidência de podridão apical dos frutos.

Tendo em vista que a tolerância das culturas à salinidade esta relacionada a vários fatores, entre eles a cultivar, este trabalho teve por objetivo avaliar o efeito da irrigação com água de diferentes níveis de salinidade na produtividade da cultura de tomate.

\section{MATERIAL E MÉTODOS}

O experimento foi conduzido em ambiente protegido localizado no Departamento de Engenharia da Universidade Federal de Lavras, Lavras-MG, situado nas coordenadas geográficas aproximadas de $21^{\circ} 14^{\prime}$ de latitude sul e $45^{\circ} 00^{\prime}$ de longitude oeste e altitude de 910 m. O clima segundo a classificação climática de Koppen é cwa. A temperatura média anual do ar é de $20,4^{\circ} \mathrm{C}$ e a precipitação média anual de 1460,0 mm (DANTAS et al., 2007).

A estufa foi coberta com polietileno transparente de 150 micras e com tratamento anti-UV e as fachadas laterais fechadas com telado. Para monitoramento das temperaturas do ar (máxima e mínima) e umidades relativas do ar (máximas e mínimas), instalou-se um termohigrômetro digital no centro do ambiente a 2,0 m de altura do solo. Também foi instalado um tanque classe A para medir a evaporação, cujas leituras foram realizadas diariamente, no período da manhã.

O solo utilizado foi um Latossolo Vermelho distroférrico (EMBRAPA, 1999) de textura argilosa, o qual foi coletado na camada superficial do solo $\left(\begin{array}{lllll}0 & \text { a } & 0,20 & \mathrm{~m} & \mathrm{de}\end{array}\right.$ profundidade). Após a coleta, o solo foi passado em uma peneira de $4 \mathrm{~mm}$, com o objetivo de reduzir os torrões. A adubação foi realizada com base na análise de fertilidade do solo e recomendações da Comissão de Fertilidade do Solo do Estado de Minas Gerais (CFSEMG, 1999). Para obtenção de 200 L de substrato, ou seja, para cada dez vasos de $20 \mathrm{~L}$, utilizaram-se $73 \mathrm{~kg}$ de areia fina peneirada, $120 \mathrm{~kg}$ de solo, 25 $\mathrm{kg}$ de composto orgânico comercial, $1 \mathrm{~kg}$ de calcário dolomitico, $0,355 \mathrm{~kg}$ de Uréia, $2,8 \mathrm{~kg}$ de Super Fosfato Simples, 0,533 kg de Cloreto de Potássio. Em cada vaso foi colocado, no fundo, um tecido de polietileno fino e $2,0 \mathrm{~kg}$ de areia fina, para facilitar a drenagem da solução salina. Posteriormente os vasos foram preenchidos com o substrato.

Os vasos foram dispostos sobre uma bancada com 0,20 m de altura, para permitir a coleta do volume de água percolada (D), e espaçamento utilizado foi de $0,60 \mathrm{~m}$ entre as plantas e 1,00 m entre as fileiras.

$\mathrm{O}$ início do experimento caracterizou-se por elevar o solo dos vasos à capacidade de 
campo; para isto saturaram-se os solos com água sem sal, envolvendo-os individualmente com plástico, de forma a forçar a perda de água apenas por drenagem. Quando cessou a drenagem (aproximadamente dois dias) retiraram-se os plásticos e procedeu-se o plantio das mudas. A cultura utilizada foi o tomate, cultivar Évora. As mudas foram transplantadas no dia 17/02/2014 sendo colocada uma planta por vaso.

O experimento foi conduzido em um delineamento inteiramente casualizado, com 5 níveis de salinidade da água de irrigação $(\mathrm{S} 1=0,05 ; \mathrm{S} 2=1,5 ; \mathrm{S} 3=3,5$ e $\mathrm{S} 4=5,5$ e $\mathrm{S} 5$ 6,5 dS $\mathrm{m}^{-1}$ a $25^{\circ} \mathrm{C}$ ) e cinco repetições.

Utilizou-se um sistema de irrigação por gotejamento, composto de cinco reservatórios (um para cada nível de salinidade da água), cabeçal de controle e registros para controle da irrigação de cada tratamento. A água foi conduzida até os vasos em tubulações de polietileno de $16 \mathrm{~mm}$. Sobre as tubulações foram inseridos emissores autocompensantes, trabalhando dentro da faixa de pressão recomendada pelo fabricante, com uma vazão nominal de $4,0 \mathrm{~L} \mathrm{~h}^{-1}$, sendo um gotejador por planta.

Após a montagem e distribuição do sistema de irrigação, foram determinados os coeficientes de uniformidade de distribuição de água (CUD) do sistema de irrigação. Para isso, foram coletadas as vazões de todos os gotejadores do sistema. A vazão média do sistema obtida foi de $4,02 \mathrm{~L} \mathrm{~h}^{-1}$, e o coeficiente de uniformidade de distribuição de água (CUD) obtido foi $98,13 \%$.

A evapotranspiração diária da cultura (ET) para cada tratamento foi determinada pela diferença entre a lâmina de água aplicada via irrigação (I) e a lâmina de água percolada (D), conforme (eq. 1).

$$
\mathrm{ET}=\mathrm{I}-\mathrm{D}
$$

Relacionando-se os valores de ET e evaporação do tanque classe A (Ev) (eq. 2), obteve-se um coeficiente " $\mathrm{K}$ " ajustado para cada um dos tratamentos utilizados:

$$
\mathrm{K}=\frac{\mathrm{ET}}{\mathrm{Ev}}
$$

O sal utilizado no experimento foi $\mathrm{o}$ Cloreto de sódio $\mathrm{NaCl}$, puro para análise. Para se determinar a quantidade de sal necessária para produzir os níveis de condutividade elétrica (CE), foram preparadas soluções salinas com concentrações de $100 ; 90 ; 80 ; 70 ; 60 ; 55 ; 50$; $45 ; 40 ; 35 ; 30 ; 25 ; 20 ; 15 ; 10 ; 8 ; 6 ; 4$ e 2 meq L 1 . Depois de feitas a leitura da condutividade elétrica obteve-se, por meio de regressão, a curva da relação de concentração versus condutividade elétrica. Obteve-se uma equação quadrática (eq. 3), a partir da qual, era obtida a quantidade de sal necessária para a condutividade elétrica relativa a cada tratamento.

$$
\mathrm{QS}=-2,2212+9,5535 \mathrm{CE}+0,0132 \mathrm{CE}^{2}
$$

em que,

QS - quantidade de sal $(\mathrm{NaCl})$, meq $\mathrm{L}^{-1}$;

$\mathrm{CE}$ - condutividade elétrica, $\mathrm{dS} \mathrm{m}^{-1}$.

O desbaste foi realizado nas brotações laterais, conforme a necessidade da cultura. Foi realizado um controle sistemático de pragas e doenças com aplicações preventivas de defensivos.

Foram realizadas análises quantitativas e qualitativas da produção da cultura do tomate, e do seu crescimento, analisando-se o diâmetro e altura das plantas ao longo do ciclo. Ao final da colheita, os frutos foram avaliados quantitativamente, peso e número, e qualitativamente, medindo-se o diâmetro do fruto e classificando-os conforme Portaria $\mathrm{n}^{0}$ 553 de agosto de 1995 do Ministério da Agricultura. Em cada vaso foram coletadas amostras do solo para determinação da salinidade do solo estimada pela condutividade elétrica do extrato de acordo com metodologia proposta pela Embrapa (1997). A altura da 
planta foi medida com trena e o diâmetro do caule medido com paquímetro digital. A área foliar foi avaliada no final do ciclo da cultura utilizando um integrador de área (modelo LI 3000 da Licor Inc.). A parte aérea da planta foi pesada (folha, pecíolo e caule) e levada para estufa ventilada com temperatura de $65{ }^{\circ} \mathrm{C}$ e, após um período de 72 horas o material foi pesado e calculado a matéria seca.

Os dados obtidos foram submetidos à análise de variância a 1 e 5\% de significância através de regressão. As análises estatísticas foram realizadas utilizando-se o software SISVAR versão 5.3 (FERREIRA, 2011).

\section{RESULTADOS E DISCUSSÃO}

A colheita foi iniciada aos 74 dias após transplantio (DAT), em 22/04/14 e encerrada em 11/05/14 (93 DAT) computando um total de seis colheitas.

$\mathrm{Na}$ Figura 1 é apresentada a relação entre a evapotranspiração da cultura e evaporação do tanque Classe A, medidos diariamente durante o ciclo da cultura. Verifica-se que a relação diminuiu á medida que aumenta a concentração de sal na água de irrigação. Aproximadamente até 20 dias após o transplantio (DAT) os valores da relação ET/EV apresentaram tendências semelhantes, posteriormente a taxa de acréscimo na relação ET/EV nos tratamentos com 0,05 e $1,5 \mathrm{dS} \mathrm{m}^{-1}$ foi acentuada. Nos tratamentos com maiores concentrações de sal, de 3,5 até $6,5 \mathrm{dS} \mathrm{m}^{-1}$ os valores de ET/Ev oscilaram entre 0,20 e 0,60 e no final do ciclo ficou em torno de 0,3 . No tratamento de $1,5 \mathrm{dS}$ $\mathrm{m}^{-1}$ atingiu valor 1,0 entre 35 e 45 DAT e a seguir reduziu atingindo valores próximos de 0,7 . No tratamento com água sem adição de sal atingiu valores próximo de 1,3 aos 45 DAP reduzindo a seguir, porém mantendo valores superiores a 1,0. Estes dados mostram o efeito do aumento da salinidade no desenvolvimento da parte área da planta, pois de acordo com Romeroaranda et al. (2001), a salinidade provoca uma redução no número e na área foliar. Os autores verificaram que a taxa de transpiração, a taxa de assimilação líquida de $\mathrm{CO} 2$ e a condutância estomática foram significativamente reduzida pela salinidade em duas cultivares de tomate.

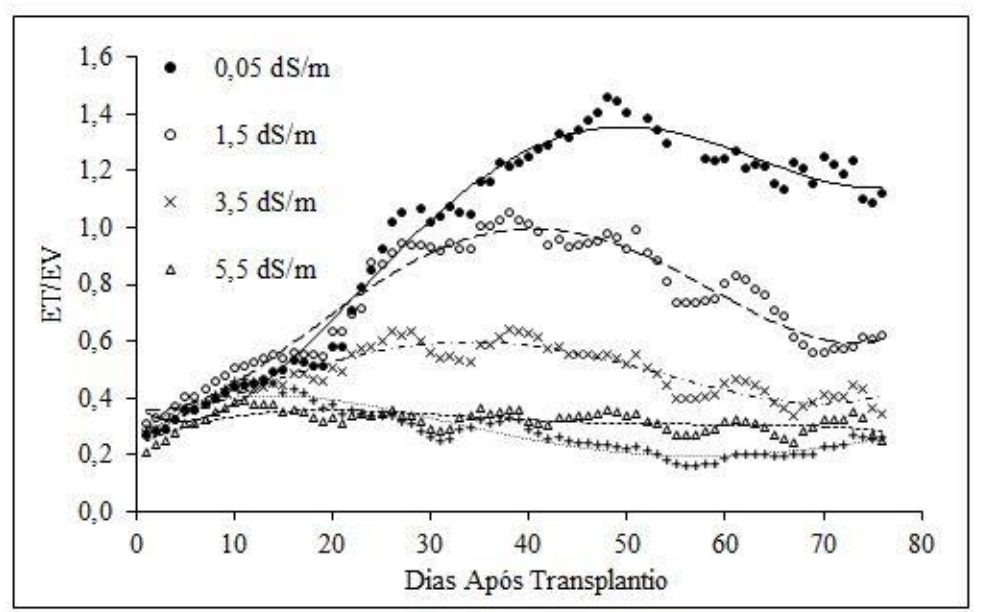

Figura 1. Relação entre a evapotranspiração da cultura e a evaporação do tanque Classe A durante o ciclo da cultura do tomate

Os dados de altura da planta e diâmetro do caule estão representados na Figura 2. Como pode ser observado as plantas irrigadas com água com menor nível concentração de sal $(0,05$ 
Viol et al.

e 1,5 dS m $\mathrm{m}^{-1}$ ) a altura e diâmetro de caule tendem a ser maiores do que nos demais tratamentos. A taxa de crescimento, tanto para altura quanto para o diâmetro de caule tende a ser menor nos tratamentos irrigados com níveis de concentração de sal na água de 3,5, 5,5 e 6,5 $\mathrm{dS} \mathrm{m}{ }^{-1}$. Oliveira et al. (2007), trabalhando com tomate cultivado em casa de vegetação e utilizando água de característica salina em diferentes diluições com água de chuva, verificaram que os diferentes níveis de sais na água reduziu significativamente a altura da planta sendo observado uma redução da ordem de $4,6 \mathrm{~cm}$ na altura da planta para cada acréscimo unitário na condutividade elétrica da água.

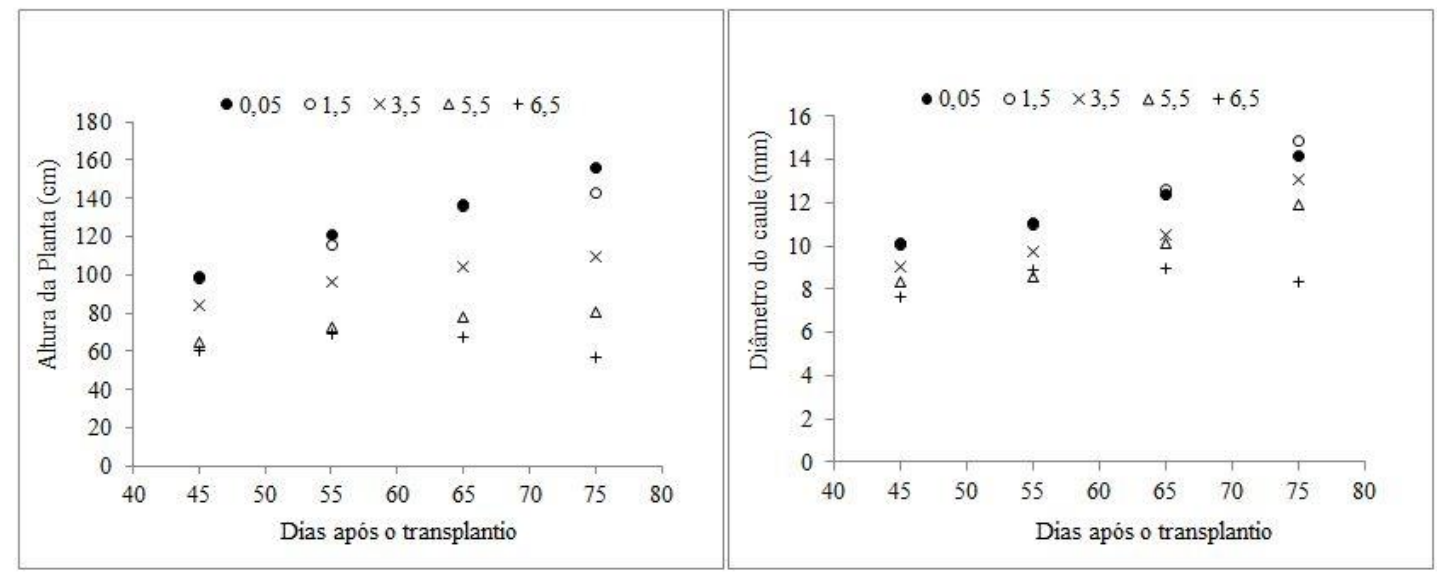

Figura 2. Dados de altura e diâmetro de caule da planta durante o ciclo em função dos níveis de salinidade da água de irrigação

Estudos realizados por Bao e Li (2010), com a cultura de tomate cultivado em ambiente protegido foi verificado que a altura da planta e o diâmetro do caule foram influenciados pela salinidade da água, porém as alterações foram significativas somente nos experimentos conduzidos no verão em que a salinidade da água foi $16,67 \mathrm{dS} \mathrm{m}^{-1}$. Segundo os autores, porque provavelmente, no verão as plantas crescem muito mais rapidamente do que na primavera, devido as altas temperaturas e radiação solar, portando acentuando os efeitos negativos da salinidade sobre o crescimento.

Resultados de pesquisa com a cultura do tomate (Guedes et al., 2015 e Oliveira et al., 2007; Vieira et al., 2016) indicam que a área foliar e matéria seca da parte aérea da planta reduz com o aumento da salinidade. Como pode ser observada na Figura 3, a área foliar e a matéria seca da parte aérea da planta, reduziram com o aumento da salinidade da água de irrigação. 


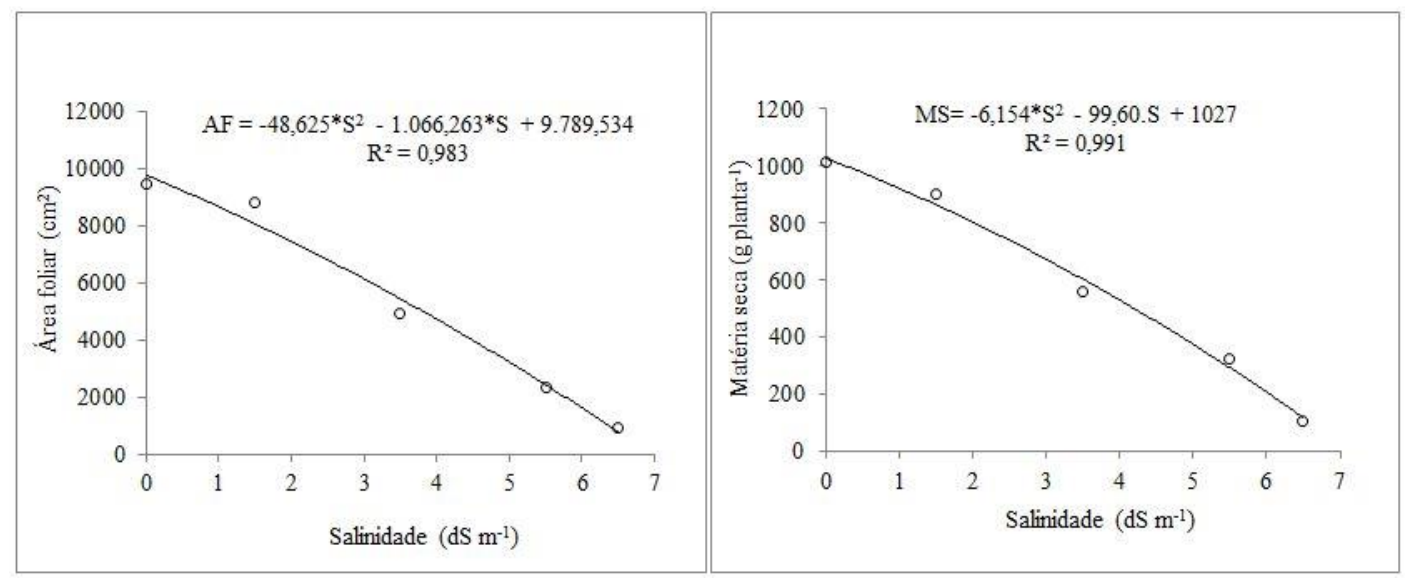

Figura 3. Dados de área foliar (AF) e matéria seca (MS) da parte aérea do tomate em função dos níveis de salinidade da água

De acordo com Guedes et al. (2015), a emissão e/ou senescência foliar devido ao efeito negativo da salinidade demonstram a sensibilidade das folhas à salinidade apresentando redução no tamanho e no número de folhas na presença de elevadas concentrações de sais. Segundo Taiz e Zieger (2009), a redução da matéria seca da parte aérea está relacionada a modificações das atividades metabólicas das células que limitam a elasticidade da parede celular reduzindo a alongamento da parede celular, consequentemente ocorre uma redução no crescimento da planta.

A produção média total e comercial da cultura esta apresentada na Figura 4. Observase que tanto a produção total quanto a produção comercial, reduziram com o aumento da salinidade atingindo valores de 146,9 e 96,7 gramas por plantas no tratamento irrigado com maior nível de salinidade $\left(6,5 \mathrm{dS} \mathrm{m} \mathrm{m}^{-1}\right)$. A produção comercial foi mais afetada pela salinidade do que a produção total, sendo que para cada unidade de acréscimo na salinidade da água a redução na produção comercial foi de 133,6 g por planta. Eloi et al. (2007), verificaram que a produção total e comercial do tomateiro foi significativamente influenciada pelos diferentes níveis de salinidade, apresentando uma redução relativa na produtividade de $10,95 \%$ para cada acréscimo de uma unidade da salinidade do solo. Medeiros et al. (2012), registrou um decréscimo relativo na produtividade de $15,96 \%$ para cada aumento de uma unidade da salinidade do solo. Em trabalho realizado por Campos et al. (2006), com a cultura de tomate submetido a cinco níveis de salinidade (condutividade elétrica da água de $1,2,3,4$, e $5 \mathrm{dS} \mathrm{m}^{-1}$ ) foi observado que a produtividade total e comercial foi significativamente influenciada pela salinidade. A produtividade comercial foi de 3,191 g planta -1 para o tratamento irrigado com água de $1 \mathrm{dS}$ $\mathrm{m}^{-1}$ enquanto que a menor produtividade, de $1,538 \mathrm{~g} \mathrm{planta}^{-1}$, foi obtida no tratamento irrigado com água de $5 \mathrm{dS} \mathrm{m}^{-1}$. 
Viol et al.

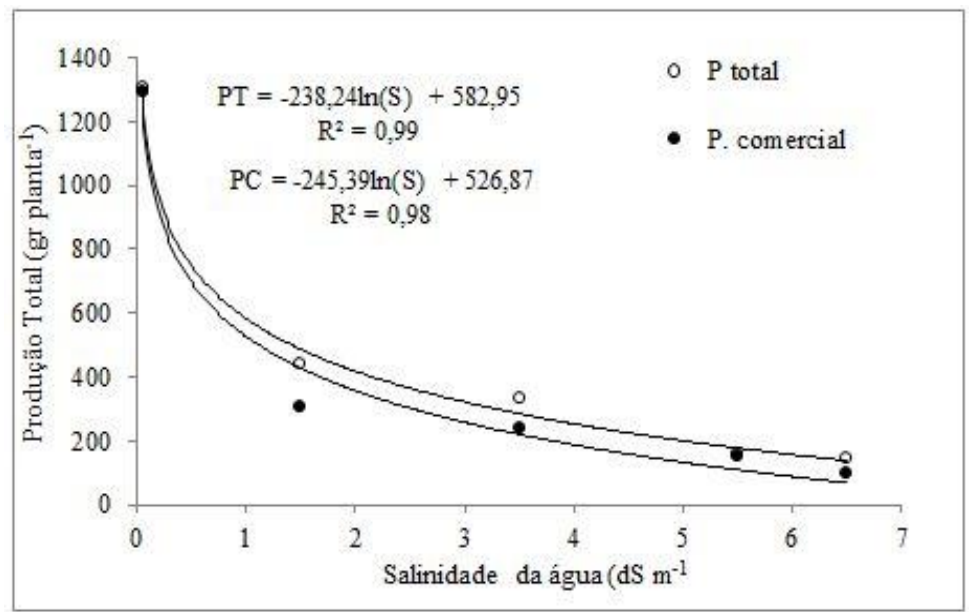

Figura 4. Produção total e comercial do tomate em função dos níveis de salinidade da água de irrigação

Pode-se observar na Tabela 1 que a queda de produção total nos tratamentos irrigados com água salina variou de $66,5 \%$ a $88,7 \%$ e na produção comercial variou de $76,5 \%$ a $92,5 \%$.
Quando a salinidade da água de irrigação aumentou de 0,05 para $1,5 \mathrm{dS} \mathrm{m}^{-1}$ a queda na produção total e comercial foi superior a $66,5 \%$ e $76,5 \%, \quad$ respectivamente.

Tabela 1. Queda de produção (\%) total e comercial em função dos níveis de salinidade da água de irrigação

\begin{tabular}{ccc}
\hline $\begin{array}{c}\text { Tratamentos } \\
\left.(\mathrm{dS} \mathrm{m})^{-1}\right)\end{array}$ & $\begin{array}{c}\text { Queda produção total } \\
(\%)\end{array}$ & $\begin{array}{c}\text { Queda produção comercial } \\
(\%)\end{array}$ \\
\hline 0,05 & 0,0 & 0,0 \\
1,5 & 66,5 & 76,5 \\
3,5 & 74,6 & 81,7 \\
5,5 & 87,8 & 88,3 \\
6,5 & 88,7 & 92,5 \\
\hline
\end{tabular}

O maior percentual de frutos refugados foi observado no tratamento em que as plantas foram irrigadas com água de maior concentração de sal. Medeiros et al. (2012), relatam que elevadas taxas de perdas de produtividade observada nos níveis mais elevados de salinidade do solo se deve, principalmente, ao problema fisiológico fundo preto dos frutos, seguido de deformações e frutos pequenos.

Na Figura 5 estão relacionados os dados de produção comercial do tomate em função da salinidade média do extrato obtido na pasta de saturação do solo. Observa-se que a concentração de sais no solo aumentou significativamente com o aumento da condutividade elétrica da água de irrigação. Mesmo no tratamento testemunha $\left(0,05 \mathrm{dS} \mathrm{m}^{-1}\right.$ na água de irrigação) a condutividade elétrica no extrato de saturação do solo atingiu valor médio de 2,31 $\mathrm{dS} \mathrm{m}^{-1}$, devido aos sais fertilizantes aplicados durante o ciclo da cultura. Segundo Medeiros et al. (2012), parte dos sais fertilizantes adicionados no solo via água de irrigação é consumida e o restante deposita nos colóides do solo com potencial para aumentar a concentração, sobretudo após sucessivas aplicações, chegando ao ponto de reduzir o desenvolvimento e o rendimento das culturas. 


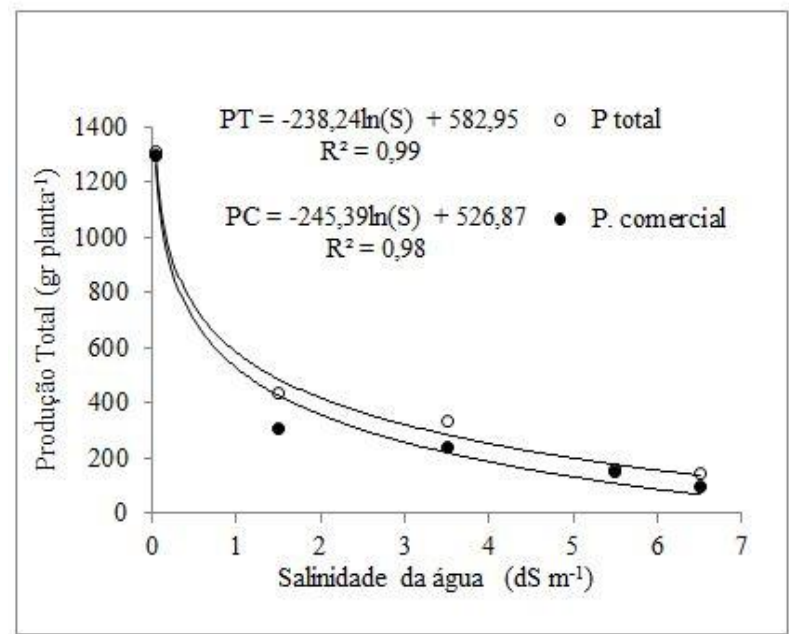

Figura 5. Produção total do tomate em função dos níveis de salinidade do extrato saturado do solo

De acordo com Ayers e Westcot (1991) para uma produção potencial de $100 \%$ da cultura de tomate, em função da condutividade elétrica da água de irrigação e do extrato saturado do solo é de $1,7 \mathrm{dS} \mathrm{m}^{-1}$ e $2,5 \mathrm{dS} \mathrm{m}^{-1}$, respectivamente. No tratamento em que a condutividade elétrica da água de irrigação foi de $1,5 \mathrm{dS} \mathrm{m}^{-1}$, valor inferior ao preconizado na literatura acima citada, a produção comercial reduziu significativamente quando comparada ao tratamento de $0,05 \mathrm{dS} \mathrm{m}^{-1}$.

Tal resultado é, possivelmente, devido ao aumento da salinização do solo durante o ciclo da cultura, pois no final do experimento a condutividade elétrica medida no extrato de saturação do solo atingiu valor médio de 20,1 $\mathrm{dS} \mathrm{m} \mathrm{m}^{-1}$.

A Figura 6 apresenta os dados de classificação (grande, médio e pequeno) para o número e o peso dos frutos de tomate em função dos níveis de salinidade da água de irrigação.
Pode ser observado que, tanto para o número quanto para o peso de frutos no tratamento irrigado com água cuja condutividade elétrica foi de $0,05 \mathrm{dS} \mathrm{m}^{-1}$, a maior ocorrência foi de frutos de tamanho grande. Nos tratamentos irrigados com água salina predominou frutos de tamanho pequeno. Com relação ao peso de frutos nos tratamentos irrigados com água de 1,5 e $3,5 \mathrm{dS} \mathrm{m}^{-1}$, prevalece frutos de peso médio. Já nos tratamentos com maior concentração salina houve maior ocorrência de frutos cujo peso é classificado como pequeno.

A classificação do produto auxilia na comercialização e tem um papel econômico significativo, tanto para o vendedor quanto para o comprador, seja no comércio interno quanto no externo. De acordo com Andreuccetti et al. (2004) a classificação adotada no mercado para o tomate valoriza o tamanho, pois quanto mais graúdo, maior o valor comercial. 


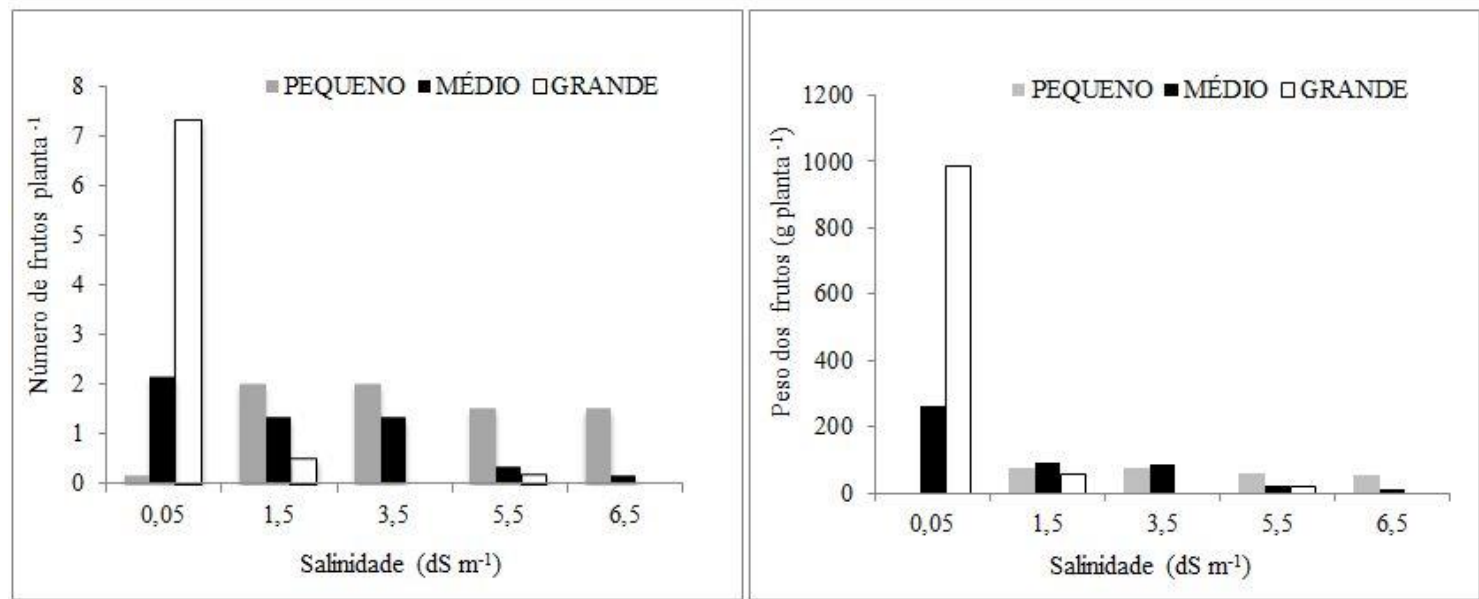

Figura 6. Dados de classificação para o número e o peso de frutos em função dos níveis de salinidade da água de irrigação

\section{CONCLUSÕES}

- O aumento da salinidade da água de irrigação promoveu redução nas características de crescimento da planta (altura e diâmetro do caule), na produção total e comercial e no número de frutos.

- A produção comercial foi mais afetada pela salinidade da água do que a produção total.

- A condutividade elétrica medida no extrato de saturação do solo, no final do experimento, aumentou com o aumento da concentração salina da água de irrigação, com valores médios variando de 2,31 a $29,8 \mathrm{dS} \mathrm{m}^{-1}$.

\section{AGRADECIMENTOS}

Os autores agradecem à Fundação de Amparo à Pesquisa do Estado de Minas Gerais - FAPEMIG pelo apoio financeiro ao projeto.

\section{REFERENCIAS}

ANDREUCCETTI, C.; FERREIRA, M. D.; GUTIERREZ, A. S. D.; TAVARES, M.
Classificação e padronização dos tomates cv Carmem e Débora dentro da CEAGESP - SP, Engenharia Agrícola, v. 24, n. 3, p. 790-798, 2004.

AYERS, R. S.; WESTCOT, D. W. A qualidade da água na agricultura. Tradução de Gheyi, R. H.; Medeiros, J. F. de; Damasceno, F. A. V. 1991, 218p. (Estudos FAO: Irrigação e Drenagem, 29, Revisado).

BAO, H.; LI, Y. Effect of stage-specific saline irrigation on greenhouse tomato production, Irrigation Science, v.28. n.5, p. 421-430, 2010.

CAMPOS, C. A. B.; FERNANDES, P. D.; GHEYI. H. R.; BLANCO, F . F.; GONÇALVES, C. B.; CAMPOS, S. A. F. Yield and fruit quality of industrial tomato under saline irrigation, Scientia Agricola, v. 63, n.2, p. 146-152, 2006

CANTORE, V.; PACE, B.; MLADEN, T.; PALMA, E. de; BOARI, F. Influence of salinity and water regime on tomato processing, Italian Journal of Agronomy, v. 7, n.1, p. 6470,2012

CLIFF, M. A.; LI. J. B.; TOIVONEN. P. M. A.; EHRET, D. Effects of nutrient solution 
EFEITO DA SALINIDADE NO CRESCIMENTO E PRODUÇÃO DO TOMATE CULTIVADO EM AMBIENTE PROTEGIDO

electrical conductivity on the compositional and sensory characteristics of greenhouse tomato fruit, Postharvest Biology and Technology, v. 74, p.132-140, 2012

DANTAS, A. A. A.; CARVALHO, L. G.; FERREIRA, E. Classificação e tendência climática em Lavras. Ciência e Agrotecnologia, v. 31, n. 6, p. 1862-1866, nov./dez. 2007.

ELOI. W. M.; DUARTE, S. N.; SOARES, T. M. Níveis de salinidade de manejo da fertirrigação sobre características do tomateiro cultivado em ambiente protegido, Revista Brasileira de Ciências Agrárias, v. 2, n.1, p. 83-89, 2007

EMPRESA BRASILEIRA DE PESQUISA AGROPECUÁRIA. Centro Nacional de Pesquisa de Solos. Sistema brasileiro de classificação de solos. Rio de Janeiro, RJ, 1999. $412 \mathrm{p}$.

EMPRESA BRASILEIRA DE PESQUISA AGROPECUÁRIA. Centro Nacional de Pesquisa de Solos. Manual de Métodos de Análise de Solo. Rio de Janeiro, RJ, 1997. 212 p.

FERREIRA, D.F. SISVAR: Um sistema computacional de análise estatística. Ciência e Agrotecnologia, v.35, p.1039- 1042, 2011.

GUEDES, R. A. A.; OLIVEIRA, F. de A. de; ALVES, R. de C.; MEDEIROS, A. C. de; GOMES, L. P.; COSTA, L. P. Estratégias de irrigação com água salina no tomateiro cereja em ambiente protegido. Revista Brasileira de Engenharia Agrícola e Ambiental, v. 19, n 10, p.913-919, 2015.
LEOGRANDE , R. LOPEDOTA, O.; MONTEMURRO, F.; VITTI, C.; VENTRELLA, D. Effects of irrigation regime and salinity on soil characteristics and yield of tomato, Italian Journal of Agronomy, v. 7, n.1, p. 50-57, 2012.

MALASH, N.; FLOWERS, T. J.; RAGAB, R. Effect of irrigation systems and water management practices using saline and nonsaline water on tomato production, Agricultural Water Management, v. 78, n. 12, p.25-38, 2005.

MALASH, N. M.; ALI, F.; FATAHALLA, M. A; KHATAB, E. A.; HATEM, M. K.; TAWFIC, S. Response of tomato to irrigation with saline water applied by different irrigation methods and water management strategies, International Journal of Plant Production, v.2, n.2, p. 101-116, 2008.

MASS, E. V.; HOFFMAN, G. J. Crop salt tolerance - current assessment, Journal of Irrigation and Drainage Division, v. 103, p. 115-134, 1977.

MEDEIROS, P. R. F.; DUARTE, S. N.; UYEDA, C. A.; SILVA, E. F. F.; MEDEIROS, J. F. de. Tolerância da cultura do tomate à salinidade do solo em ambiente protegido, Revista Brasileira de Engenharia Agrícola e Ambiental, v.16, n.1, p. 51-55, 2012.

OLIVEIRA, B. C.; CARDOSO, M. A. A.; OLIVEIRA, J. C. de; OLIVEIRA, F. A. de; CAVALCANTE, L. F. Características produtivas do tomateiro submetido a diferentes níveis de sais, na água de irrigação, Revista Brasileira de Engenharia Agrícola e Ambiental, v. 11, n.1, p. 11-16, 2007. 
Viol et al.

ROMERO-ARANDA, R.; SORIA, T.; water and nitrogen fertilization, CUARTERO, J. Tomato plant- water uptake Revista Brasileira de Engenharia Agrícola e and plant-water relationship under saline growth conditions, Plant Science, v. 160, n. 2, p.265272, 2001.

TAIZ, L.; ZIEGER, E. Plant Physiology, 3. ed., Porto Alegre: Artmed, 2009, 709p.

VEIRA, I. G. S.; NOBRE, R. G.; DIAS, A. S.; PINHEIRO, F. W. A. Cultivation of cherry tomato under irrigation with saline Ambiental, v. 20, n.1, p. 55-61, 2016.

WAN, S.; KANG, D.; LIU, S-P.; FENG, L-P. Effect of drip irrigation with saline water on tomato (Lycopersicon esculentum Mill) yield and water use in semi-humid area. Agricultural Water Management, v. 90, n. 1-2, p. 63-74, 2007. 